\title{
Effectiveness of a Multidisciplinary Approach Intervention to Improve Blood Pressure Control Among Elderly Hypertensive Patients in Rural Thailand: A Quasi-Experimental Study
}

This article was published in the following Dove Press journal:

Journal of Multidisciplinary Healthcare

\author{
Nanthakan Sungsuman \\ Woodham (D)' \\ Surasak Taneepanichskul' \\ Ratana Somrongthong' \\ Apaporn Kitsanapun ${ }^{2}$ \\ Benjapan Sompakdee ${ }^{3}$ \\ 'College of Public Health Sciences, \\ Chulalongkorn University, Bangkok, \\ Thailand; ${ }^{2}$ Sirindhorn College of Public \\ Health Suphanburi, Suphan Buri, Thailand; \\ ${ }^{3}$ Buengkan District Health Office, Bueng \\ Kan, Thailand
}

Purpose: Uncontrolled blood pressure among Thai elderly hypertensive patients is a significant public health issue in primary health care facilities under the Universal Health Coverage Scheme in Thailand. This study examines the effectiveness of a multidisciplinary approach intervention to improve blood pressure control among elderly persons in rural Thailand.

Patients and Methods: This was quasi-experimental study conducted on 200 elderly persons who receive care for hypertension at primary health care facility in rural areas of Thailand. Participants were assigned to either the intervention or control groups. The intervention group was subjected to a multidisciplinary approach intervention program. This program included community-based care for hypertension, family-supportive care for hypertension, antihypertension medication adherence education program, the use of a reminder electronic pill box, and monthly pill counts and blood pressure measurements. The intervention continued for three months. The control group received care for hypertension at the hypertension clinic of the health center. Three measurements were taken at baseline, one month, and three months after the intervention. Data analysis included descriptive statistics and independent sample $t$-tests. Repeated-measure analysis of variance (ANOVA) and analysis of covariance (ANCOVA) were used to compare the differences between the two groups.

Results: At one month and three months after the intervention, the multidisciplinary approach intervention controlled blood pressure more effectively compared with the control group. Furthermore, the intervention group had lower systolic and diastolic blood pressure compared with the control group ( $\mathrm{P}$-value $<0.001$ ).

Conclusion: These results suggest that the multidisciplinary approach intervention can be effective in controlling blood pressure in elderly hypertensive patients. Future studies should investigate a cost-effective means of integrating multidisciplinary approach interventions in routine hypertension care for elderly hypertensive patients.

Keywords: hypertension, universal health coverage, primary health care, community base intervention

\section{Introduction}

Hypertension is a significant public health problem that is responsible for millions of deaths worldwide. ${ }^{1,2}$ In Thailand, an earlier survey showed an increased prevalence of hypertension among individuals aged 15 years and over. Furthermore,
Correspondence: Surasak

Taneepanichskul

College of Public Health Sciences,

Thailand

Tel +66-2218-8153

Fax +66-2255-6046

Email academic_cphs@chula.ac.th 
hypertension is especially prevalent among elderly persons. ${ }^{3,4}$ The treatment cost for hypertension is enormous, considering the number of patients and families impacted. ${ }^{5}$ Since 2002, the rising burden of noncommunicable diseases led the Royal Thai government to include the treatment of hypertension in the Universal Health Coverage (UHC) benefits package. ${ }^{6}$ All treatment and laboratory testing for hypertension monitoring is provided free of charge to all Thai citizens in the primary health care system. $^{7}$

Uncontrolled blood pressure among patients treated for hypertension is a major problem in Thailand, and has become a significant public health problem under the UHC. $^{3,8}$ A report from the Department of Disease Control, Ministry of Public Health showed an increase in the number of deaths caused by cerebrovascular diseases and coronary artery disease. Two-thirds of stroke cases and half of ischaemic heart disease cases were attributed to hypertension. ${ }^{9,10}$

Of the estimated 13.2 million people living with hypertension, approximately 2.5 million receive treatment but fail to control their blood pressure. ${ }^{11}$ In 2014, the number of patients who received treatment and were yet unable to achieve blood pressure control to $<140 / 90 \mathrm{~mm} \mathrm{Hg}$ was $70.3 \%$. This means that only $29.7 \%$ were able to bring their blood pressure control within the desired range. If hypertension is more effectively controlled, the number of deaths from cardiovascular diseases will be reduced. Furthermore, the incidence of stroke would also be reduced, which may also reduce the high cost associated with long-term care in the primary health care system covered by the UHC. ${ }^{11}$

The reasons for the difficulty in controlling hypertension among Thai patients are diverse. Studies have reported various causes of uncontrolled blood pressure among hypertensive patients. The causes include a lack of awareness of the condition and a lack of understanding of normal variations in blood pressure measurement, because hypertensive patients often show no symptoms. Furthermore, some patients living in remote areas refused to avail of proper monitoring and treatment, owing to the inconvenience of attending and keeping regular appointments at the hypertension clinic. Crowded clinics and long waiting times for treatment at the health facility have also been reported among the causes. ${ }^{12-14}$

Moreover, patients might not adhere to regular schedules for medication, or may have difficulty in taking various drugs. In addition, the insufficient attention from health-care providers to provide adequate information to patients has been cited as another challenge, as well as a lack of attention to make the necessary adjustments to medication when patients fail to effectively control their blood pressure. ${ }^{13,14}$

Successful strategies to improve blood pressure control among hypertensive patients involve multiple interventions. Many studies recommend various complex interventions that appear to be more effective than any single intervention. ${ }^{15,16}$

In rural areas of Thailand, where the UHC provides a health service to all populations, accessibility to healthcare facilities remains a challenge. Elderly persons with hypertension have difficulty in controlling their blood pressure owing to the various causes mentioned above. Although the multidisciplinary approach has been strongly recommended to improve blood pressure control, evidence to support the most effective strategies for health-care providers and decision makers to design an appropriate program is still lacking.

Current strategies are mostly focused on the single education program intervention conducted at a health facility (either health centers or district hospitals). The multidisciplinary approach adopted in this study included a multidisciplinary health-care team taking multiple approaches to improve blood pressure control at the community level. The intervention also incorporated family support in hypertension care, an antihypertensive medication adherence education program, the use of a reminder electronic pill box, and monthly pill counts and blood pressure measurements.

The intervention was developed based on a feasible solution available to rural areas of Thailand, where limited resources and transportation remain challenges. This study was conducted in Buengkan Province, which is considered a low-income, remote area on the Thai-Laos border in northeast Thailand, with a high number of elderly hypertensive patients with uncontrolled blood pressure. ${ }^{17}$ Access to health facilities in this province is a challenge because of the lack of public or affordable transportation to get from the patient's village to the health facility.

This study aimed to investigate the effectiveness of a multidisciplinary intervention to improve blood pressure control among elderly hypertensive patients in rural Thailand. The results and recommendations may provide valuable evidence and inform health-care providers at all levels in the effective design of interventions to improve blood pressure control among hypertensive patients and improve the quality of care. Effective interventions should 
complement the UHC by increasing equal access to health care and improving equity for all.

\section{Patients and Methods}

The study was a quasi-experimental study. It was designed to test the effectiveness of the multidisciplinary intervention compared with the control, in improving blood pressure control among previously uncontrolled elderly hypertensive patients in Noonsomboon Health Center in Buengkan District, Buengkan Province. This health center is visited by a high number of elderly hypertensive patients with poorly controlled blood pressure.

\section{Study Area}

This study was conducted in Buengkan Province. Thailand is comprised of 77 provinces. Buengkan Province is the most recently established province. There is a lack of public transportation, and travel from one place to another can be expensive for most elderly patients. The Thailand Ministry of Public Health operates health-care services through provincial health offices. Each provincial health office coordinates with the district health offices, which administer health centers at the subdistrict level. These health centers manage health promotion, health prevention, and rehabilitation services. Noonsomboon Health Center was purposely selected because it has highest number of elderly hypertensive patients with uncontrolled blood pressure. All Thai nationals receive health-care services from this health center free of charge, which is covered by the UHC Scheme.

\section{Study Population and Sample}

The study population comprised 3150 elderly hypertensive registered patients in Buengkan Provincial Health Office, and there were 372 elderly patients received hypertension treatment at the Noonsomboon Health Center. For this study, hypertension means Systolic Blood Pressure (SBP) $\geq 140$ $\mathrm{mmHg}$ and/or Diastolic Blood Pressure (DBP) $\geq 90 \mathrm{mmHg}$, with reference to office BP measurement. Noonsomboon Health Centers supports 13 villages under its administration. These 13 villages under its administration were grouped into two zones by using distance from the villages to the health center to separate the zone. The division into two zones is a benefit for more effective management of the health-care workforce and services. The distance between village zone one and village zone two is approximately $10 \mathrm{~km}$. Zone one was randomly assigned as an intervention group and zone two was randomly assigned as a control group.

\section{Sample Size Calculation}

The sample size was calculated using the $\mathrm{G}^{*}$ power program to obtain estimates of the desired precision. Based on a previous study, ${ }^{18}$ the effect size of 0.5 , alpha level of 0.05 , and power of 0.95 were used. The total minimum sample size was determined to be 181 participants. After adding an attrition rate of $10 \%$ to account for dropouts. The total sample size was 200 , therefor 100 participants were needed from each arm.

\section{Inclusion and Exclusion Criteria}

To be eligible for inclusion in this study, patients had to meet all the following criteria: 1) hypertensive and aged 60-79 years; 2) uncontrolled blood pressure (either systolic blood pressure $>140 \mathrm{mmHg}$ or diastolic blood pressure $>90 \mathrm{mmHg}$ ) at the last three hypertension clinic visits, recorded in the family folders at the health center; 3 ) historical evidence of noncompliance with their antihypertensive medication prescriptions in the medical records at the clinic in the last three months; 4) taking at least one antihypertensive medication per day and self-managing their medication. Patients with a hearing or cognitive impairment, and those who were unwilling to participate in the study were excluded.

\section{Participant Recruitment}

Elderly hypertensive patients who met the inclusion criteria and voluntarily joined the study were invited to participate in the study. In Zone one there were 121 patients met inclusion criteria and in Zone two there were 116 persons met inclusion criteria. A total of 200 patients participated in this study. There were 100 patients randomly selected from village zone one and were assigned for intervention group. There were 100 patients from village zone two were randomly selected and assigned for control group. The researcher provided general information on the study and its objectives. The consent form was signed by participants at the hypertension clinic of Noonsomboon Health Center. The participants were asked to bring their leftover medication when visiting the clinic.

\section{Control Group}

Elderly hypertensive patients from village zone two under the administration of the Noonsomboon Health Center were assigned to the control group. The control group received usual care from a "one stop service" for patients receiving chronic care at the health center. The usual hypertension services were organized at the health center including: 1) 
a special Out Patient Department for hypertensive patients, organized once a month and overseen by a physician; 2) health information and services, and prescription refills by clinical nurses; 3) height and weight measurements, blood pressure measurement, and laboratory tests for renal function - the blood samples were collected and sent to the district hospital for testing, and the clinical nurses took medical histories and measured blood pressure to provide health education to individual patients; 4) clinical nurses provided medication after checking for any excess/leftover medication from the previous visit, and set the next appointment for a consultation - patients with blood pressure readings $>140 / 90 \mathrm{mmHg}$ were given monthly appointments at the health centers.

\section{Intervention Group}

Elderly hypertensive patients from village zone one under the administration of the Noonsomboon Health Center were assigned to the intervention group. Patients in intervention group receive the same monthly services at the hypertension clinic of the health center as the control group. The patients underwent a multidisciplinary intensive intervention program to improve blood pressure control. The intervention was designed to address the various reasons for the lack of blood pressure control. The various components of the intervention included:

1. Community-based hypertension care program. The multidisciplinary health-care team conducted the program in the community. The community-based hypertension care was patient-centric, and close to their homes (in Thai, "Krai Ban Krai Jai," which means "near a home, near the heart"). The team comprised four clinical nurses, two public health personnel who were trained in pharmacy, and five community health volunteers for each village. The team organized the hypertension care service center in the community, once a month on Monday afternoons, for three months. The hypertension care service, including opportunistic screening for all, refilling of prescribed medications according to patient needs, blood pressure measurements, and home-based care for hypertensive patients with complications and bedridden patients.

2. The community health volunteer conducted the community hypertension education session through a loudspeaker in the village, once a week on Monday mornings, for three months. The education session over loudspeakers lasted $15 \mathrm{~min}$ and allowed community members to ask questions. The education session was focused on hypertension, and included information on blood pressure determination, physiology of hypertension, antihypertensive medication, and health behavioral patterns to prevent and control hypertension.

3. Comprehensive home visits were conducted twice a month for three months by the multidisciplinary team. The team collected information on the patient's daily lifestyle, including health-related behavior regarding physical exercise, diet, alcohol consumption, smoking habits, recreational activities to reduce stress, and other habits regarding the administration of antihypertensive medication. The data were recorded in the family folders and used to design long-term lifestyle modifications appropriate for each patient.

Long-term lifestyle modifications to control blood pressure for each patient were designed based on recommendations from the Thai Guidelines on the treatment of hypertension 2012, updated 2015 as follows:

(i) Weight reduction in overweight patients: attempts should be made to maintain a body mass index (BMI) from $18.5-22.5 \mathrm{~kg} / \mathrm{m}^{2}$ and waist circumference within Thai standards, which is $<90 \mathrm{~cm}$ for men and $<80 \mathrm{~cm}$ for women.

(ii) Modification for the consumption of healthy food: patients should consume all five food groups during every meal in appropriate portions.

(iii) Limiting the amount of salt and sodium in food: daily consumption of no more than 2 gram of sodium per day. Stricter control of sodium to no more than $1.5 \mathrm{~g}$ per day.

(iv) Increasing regular physical activity: physical exercise to achieve $>50-70 \%$ of the maximum heart rate by age (maximum heart rate was calculated by subtracting the age from 220) for an average total of 150 min per week.

(v) Limiting or avoiding alcoholic beverages: patients who never consumed alcohol were advised to continue to avoid drinking. Patients who drank alcohol were advised to limit their intake to no more than one standard drink per day for women, and no more than two standard drinks per day for men.

(vi) Stop smoking: patients who smoked were advised to stop smoking. 
1. Encouraging family members to support the elderly hypertensive patient in blood pressure control. The multidisciplinary team conducted a training session for the patient's family members in the community, once a month on Monday afternoons, for three months. At least one of the patient's family members were invited to attend the training sessions. The family member learned about the patient's behavioral change program and was encouraged to assist and support hypertensive patients in modifying their long-term lifestyle. The training topics for family members included: 1) prevention and control of hypertension; 2) how family members can encourage patients to regularly take their medication by assisting the patient in checking doses; 3) prepare food with limited amounts of fat, salt, and other sodium products; 4) reminding and supporting patients in engaging in physical exercise at least three times a week; 5) creating a recreational or relaxing environment within the family; and 6) monitoring and supporting the limiting and cessation of alcohol consumption and cigarette smoking.

2. The multidisciplinary team conducted monthly pill counts and blood pressure measurements in the community. When the clinical nurse noted poor adherence to antihypertensive medication, the cause was investigated to determine solutions to improve adherence, with participation from the patient and their family member. Patients were also discouraged from adjusting the dose of antihypertensive medicine themselves.

3. Patients were given an electronic reminder pill box to be reminded of the specific times at which medication should be taken.

4. If the multidisciplinary team had a patient with a blood pressure reading $>140 / 90 \mathrm{mmHg}$ during a home visit, the clinical nurse consulted with a physician to adjust the prescription or review the dietary program as appropriate, via telephone. The nurse would then adjust the antihypertensive medication to follow the physician's prescription and deliver the medication to the patient's home. The nurse would explain the adjustments in the prescribed medication to the patients and their families. The nurse taught patients how to prepare the medication and would ask patients to repeat the instructions, to ensure they understood the dose, type of medication, and appropriate times to take the medication.

\section{Baseline Assessment}

The baseline assessment involved the collection of data using face-to-face interviews and the World Health Organization STEPwise approach to noncommunicable disease (NCD) surveillance (STEPS) questionnaire. The data collected included sociodemographic characteristics, medication-related factors, behavioral and lifestyle factors, and comorbidities. After initial eligibility was determined, patients were asked to bring their unused or leftover medication to the health center for a baseline pill count. Medication adherence using pill count methods was evaluated by four nurses who were trained as research assistants. Patients' blood pressure measurements were recorded and blood samples were collected for laboratory testing at baseline by the same clinical nurses who were trained as research assistants.

\section{Data Collection and Measurements}

Medical adherence data and blood pressure measurements were collected for both the intervention and control groups at baseline and at one month and three months after the intervention.

\section{Medication Adherence}

Antihypertensive medication was provided for one month (30 days). For this study, the patients receive 4 types of medication which include angiotensin converting enzyme inhibitors (ACEIs), angiotensin receptor blockers (ARBs), beta blockers and calcium channel blockers (CCBs) and diuretics (thiazides). The adherence percentage was determined by counting the number of pills that was missing over a given time period, dividing by the number of pills prescribed for the same time period, and then multiplying by 100. Patients from both intervention and control groups were asked to bring their remaining medication during their monthly visits at the hypertension clinic in the health center.

\section{Blood Pressure Assessment}

The research assistants advised patients to refrain from drinking tea or coffee for at least $30 \mathrm{~min}$ before measuring the blood pressure. Patients were allowed to sit with a backrest in the waiting area, within a relaxing environment for $5 \mathrm{~min}$. Each patient's blood pressure was assessed twice while seated (2 min apart) on the same arm, using an automatic blood pressure monitor brand BV medical name OMRAN model HEM-907 size XL, Mississauga, Canada. Those measurements were used to calculate the mean 
blood pressure. The four clinical nurses who were trained as research assistants assessed blood pressure and crosschecked the measurements before recording them.

\section{Laboratory Testing}

Clinical nurses at the health center collected patients' blood samples, which were sent to the district hospital for testing. Laboratory in this study was the only one district laboratory and the same laboratory technicians. Blood samples were collected and evaluated twice, at baseline and at three months after the intervention. The laboratory test in this study determined the estimated glomerular filtration rate (eGFR). The eGFR is the test to measure the level of kidney function and determine stage of kidney disease. The eGFR is classified into 5 stages as follows;

Stage 1: eGFR in normal range (eGFR $\geq 90$ ) with other signs of kidney damage, like protein in urine or physical damage to the kidneys.

Stage 2: eGFR in normal range (60-89) with other signs of kidney damage, like protein in urine or physical damage to the kidneys.

Stage 3: eGFR 30-59, moderate kidney damage.

Stage 4: eGFR 15-29, severe kidney damage.

Stage 5: eGFR less than 15, the kidneys are close to failure or have already failed.

\section{Ethical Approval}

The study protocol was reviewed and approved by the ethical committee for Research Involving Human Subjects, Health Science Group from Chulalongkorn University (COA No.184/2560), and the Review Boards of the Ethical Committee of Buengkan Hospital (BKHEC2018-01). Committee approval is in accordance with the International Conference on Harmonization-Good Clinical Practice and the study was conducted in accordance with the declaration of Helsinki. Written informed consent were obtained from all participants. The research respected the confidentiality of all information collected from participants. A code number was assigned to each patient to protect their privacy, and confidentiality of the data was maintained.

\section{Statistical Analysis}

Descriptive statistics were used for the sociodemographic characteristics of the participants. Baseline characteristics between the intervention and control groups were compared using $t$-tests and Chi-squared tests as appropriate.
The Student's $t$-test was used to compare the mean change in blood pressure and medication adherence between the two groups. Repeated-measures analysis of variance (ANOVA) was used to compare the change in systolic and diastolic blood pressure and medication adherence. Analysis of covariance (ANCOVA) was used to compare the change in eGFR between the two groups. The effect size was calculated to quantify the effectiveness of the multidisciplinary approach in the intervention group. Statistical significance was set at $\mathrm{P}<0.05$. All analyses were performed using the SPSS version 22 software (SPSS Inc., Chicago, IL, USA) (university license).

\section{Results}

Of the 200 elderly persons with hypertension who were eligible, $100 \%$ completed the intervention period. A total of $145(72.50 \%)$ were female, and $55(27.50 \%)$ were male. The demographic and clinical characteristics of patients in both groups were compared at baseline. The baseline characteristics showed no significant differences between the intervention and control groups. The mean age and standard deviation (SD) was 67.28 (5.92) years. Most participants were married (76\%), all were literate, most had an education level lower than high school (84\%), and most worked in agriculture (66\%).

For almost half of the study participants, their partner acted as their caretaker when they were ill (48\%). Diabetes mellitus was the most common comorbidity (60.5\%). The mean baseline systolic blood pressure was $155.28 \mathrm{mmHg}$. The mean baseline diastolic blood pressure was 90.78 $\mathrm{mmHg}$. The BMI ranged from 15.62 to $29.78 \mathrm{~kg} / \mathrm{m}^{2}$. The mean eGFR was $91.77 \mathrm{~mL} / \mathrm{min} / 1.73 \mathrm{~m}^{3}$. The baseline medication characteristics were also similar between the two groups; most had been diagnosed with hypertension for 1-10 years (79\%) and took 1-2 medications per day (94.50\%). The mean (and SD) medical adherence to antihypertension medication was 53.11\% (17.17) (Table 1).

At one month and three months after the intervention, significant differences in change over time were noted between the two groups in systolic blood pressure at one month and three months after the intervention $(\mathrm{P}<0.001)$. Three months after the intervention, the mean systolic blood pressure was $141.27 \mathrm{mmHg}$ in the intervention group and $143.56 \mathrm{mmHg}$ in the control group. Significant differences change over time were also noted in diastolic blood pressure between the two groups $(\mathrm{P}=0.001)$. The mean diastolic blood pressure was $73.22 \mathrm{mmHg}$ in the intervention group and $76.69 \mathrm{mmHg}$ in the control group (Table 2). 
Table I Baseline Comparison of Characteristics of the Participants $(n=200)$

\begin{tabular}{|c|c|c|c|c|c|}
\hline Characteristics & $\begin{array}{l}\text { All Participants } \\
(\mathrm{n}=200)\end{array}$ & $\begin{array}{l}\text { Intervention } \\
\text { Group }(n=100)\end{array}$ & $\begin{array}{l}\text { Control Group } \\
(\mathrm{n}=100)\end{array}$ & $\chi^{2}$ or $t$ Value & P-value \\
\hline \multicolumn{6}{|l|}{ Demographic characteristics } \\
\hline Age, mean (SD) & $67.28(5.92)$ & $67.49(6.15)$ & $66.88(5.70)$ & 0.73 & 0.47 \\
\hline \multicolumn{6}{|l|}{ Gender, n (\%) } \\
\hline Female & $145(72.50)$ & 74 & 71 & 0.23 & 0.64 \\
\hline Male & $55(27.50)$ & 26 & 29 & & \\
\hline \multicolumn{6}{|l|}{ Marital status, n (\%) } \\
\hline No partner & $48(24.00)$ & 23 & 25 & 0.11 & 0.74 \\
\hline Married & $152(76.00)$ & 77 & 75 & & \\
\hline \multicolumn{6}{|l|}{ Education level, n (\%) } \\
\hline Lower than high school & $168(84.00)$ & 81 & 87 & 1.34 & 0.25 \\
\hline High school and higher & $32(16.00)$ & 19 & 13 & & \\
\hline \multicolumn{6}{|l|}{ Occupation, n (\%) } \\
\hline Agriculture & $132(66)$ & 62 & 70 & 1.43 & 0.23 \\
\hline Another field or not working & $68(34)$ & 38 & 30 & & \\
\hline \multicolumn{6}{|l|}{ Type of caretaker, n (\%) } \\
\hline Children & $67(33.50)$ & 33 & 34 & 0.42 & 0.98 \\
\hline Partner & $96(48.00)$ & 48 & 48 & & \\
\hline Other Daughter or son in law and relatives & $37(18.50)$ & 19 & 18 & & \\
\hline \multicolumn{6}{|l|}{ Clinical characteristics } \\
\hline \multicolumn{6}{|l|}{ Comorbidity, n (\%) } \\
\hline $\mathrm{HT}$ and DM & $|2|(60.50)$ & 58 & 63 & 0.52 & 0.47 \\
\hline $\mathrm{HT}$ and heart or kidney disease & $79(39.50)$ & 42 & 37 & & \\
\hline BMI, mean (SD) & $24.08(3.09)$ & $23.89(3.06)$ & $24.27(3.11)$ & 0.88 & 0.38 \\
\hline Systolic blood pressure, mean (SD) & $155.28(10.49)$ & $154.51(11.15)$ & $156.05(9.77)$ & 1.04 & 0.30 \\
\hline Diastolic blood pressure, mean (SD) & $90.78(5.85)$ & $90.47(6.13)$ & $91.09(5.57)$ & 0.75 & 0.46 \\
\hline \multicolumn{6}{|l|}{ Laboratory testing } \\
\hline $\begin{array}{l}\text { Estimated glomerular filtration rate (eGFR) } \\
\text { eGFR }\left(\mathrm{mL} / \mathrm{min} / 1.73 \mathrm{~m}^{3}\right)\end{array}$ & $91.77(22.31)$ & $90.66(17.97)$ & $92.87(25.98)$ & 0.70 & 0.49 \\
\hline \multicolumn{6}{|l|}{ Medication characteristics } \\
\hline \multicolumn{6}{|l|}{ Number of medications/days, n (\%) } \\
\hline $1-2$ & $189(94.50)$ & 96 & 93 & 0.87 & 0.35 \\
\hline$>2$ & II (5.50) & 4 & 7 & & \\
\hline \multicolumn{6}{|l|}{ Number of years since diagnosis, $n(\%)$} \\
\hline $1-10$ & $158(79.00)$ & 76 & 82 & 1.09 & 0.30 \\
\hline$>10$ & $42(21.00)$ & 24 & 18 & & \\
\hline Medical adherence percentage, mean (SD) & $53.11(17.17)$ & $53.63(17.50)$ & $52.60(16.92)$ & 0.42 & 0.67 \\
\hline
\end{tabular}

Abbreviations: SD, standard deviation; HT, hypertension; DM, diabetes mellitus.

A significant improvement was noted in the antihypertensive medication adherence percentage in the intervention group. The intervention group showed greater improvement in medication adherence than the control group $(72.40 \%$ vs $65.38 \%)(\mathrm{P}<0.001)$ (Table 2$)$. The
eGFR differed significantly between the two groups The mean eGFR in the intervention group was significantly higher than that in the control group $\left(96.75 \mathrm{~mL} / \mathrm{min} / 1.73 \mathrm{~m}^{3}\right.$ vs $86.11 \mathrm{~mL} / \mathrm{min} / 1.73 \mathrm{~m}^{3}$, respectively) (Table 3). 
Table 2 Group Differences in Control and Multidisciplinary Approach Intervention Groups

\begin{tabular}{|c|c|c|c|c|c|c|c|c|c|}
\hline \multirow[t]{2}{*}{ Determinant } & \multicolumn{2}{|l|}{ Baseline } & \multicolumn{2}{|c|}{$\begin{array}{l}\text { One Month Post } \\
\text { Intervention }\end{array}$} & \multicolumn{2}{|c|}{$\begin{array}{l}\text { Three Months Post } \\
\text { Intervention }\end{array}$} & \multirow[t]{2}{*}{ F Statistics } & \multirow[t]{2}{*}{ P-value } & \multirow[t]{2}{*}{$\begin{array}{l}\text { Effect } \\
\text { Size }\end{array}$} \\
\hline & Intervention & Control & Intervention & Control & Intervention & Control & & & \\
\hline Systolic BP & I54.5| (II.16) & $156.05(9.78)$ & I43.29 (I2.58) & $145.62(9.81)$ & 141.27 (13.59) & I43.56 (14.59) & 9.912 & $<0.001$ & 0.091 \\
\hline Diastolic BP & $90.47(6.13)$ & 91.09 (5.57) & $82.59(8.01)$ & 83.77 (7.47) & $73.22(8.97)$ & 79.69 & 7.120 & 0.001 & 0.067 \\
\hline $\begin{array}{l}\text { Medical } \\
\text { adherence }\end{array}$ & $53.63(17.57)$ & $52.60(16.92)$ & 71.71 (18.49) & 70.65 (20.34) & $72.40(16.06)$ & 65.38 (16.49) & 11.395 & $<0.001$ & 0.103 \\
\hline
\end{tabular}

Abbreviation: BP, blood pressure.

Table 3 Estimated Glomerular Filtration Rate (eGFR) Difference in Control and Multidisciplinary Approach Intervention Groups

\begin{tabular}{|l|l|l|l|l|l|l|l|}
\hline \multirow{2}{*}{ Laboratory Test } & \multicolumn{2}{|l|}{ Baseline } & \multicolumn{2}{l|}{ Three Months After the Intervention } & \multirow{2}{*}{ F Statistics } & P-value & Effect Size \\
\cline { 2 - 6 } & Intervention & Control & Intervention & Control & & \\
\hline eGFR $\left(\mathrm{mL} / \mathrm{min} / 1.73 \mathrm{~m}^{3}\right)$ & $90.66(17.97)$ & $92.87(25.98)$ & $96.75(13.91)$ & $86.11(20.84)$ & 17.825 & $<0.001$ & 0.083 \\
\hline
\end{tabular}

\section{Discussion}

In this study, the multidisciplinary intervention was designed to address the root cause of uncontrolled blood pressure among elderly hypertensive patients. The multidisciplinary approach intervention comprised various components to modify patient lifestyle and health-related behavior, which affect blood pressure, medical adherence, and renal function.

At one month and three months after the intervention, blood pressure control was improved. We found a significant difference in both systolic and diastolic blood pressure between the two groups. Systolic blood pressure in the intervention group was decreased from $154.51 \mathrm{mmHg}$ at baseline to $143.29 \mathrm{mmHg}$ at one month after the intervention, and after continuing the intervention for three months, the systolic blood pressure was further decreased to $141.27 \mathrm{mmHg}$. Thus, systolic blood pressure decreased over time. However, even though a decline was noted in systolic blood pressure, the measurements were still slightly higher than the recommendation for controlled blood pressure $(<140 \mathrm{mmHg})$.

Diastolic blood pressure was decreased from 90.47 $\mathrm{mmHg}$ at baseline to $82.59 \mathrm{mmHg}$ at one month and 73.22 $\mathrm{mmHg}$ at three months after the intervention. Diastolic blood pressure decreased over time and was within the recommended levels for controlled blood pressure $(<90 \mathrm{mmHg})$ for hypertensive patients. Even though we noted reductions in systolic and diastolic blood pressure in both the control and intervention groups, the intervention program was more successful than the control program in significantly decreasing the mean systolic and diastolic blood pressure values and increasing patient adherence. In the present study, we noted a reduction in blood pressure in both intervention and control groups. The reduction in blood pressure observed in the control group might have been due to the efforts of healthcare providers in explaining and increasing patient awareness of hypertension, antihypertensive medical adherence, and health-related behaviors at the hypertension clinic. However, the eGFR in the control group was deceased at three months compared to baseline ( $92.87 \mathrm{vs} .86 .11 \mathrm{~mL} / \mathrm{min} /$ $\left.1.73 \mathrm{~m}^{3}\right)$. This showed that patients in the control group had kidney damage with loss of kidney function. Medical adherence in the control group at three months after baseline was increased but remained low.

Our study showed inconsistent results from the previous systematic review that showed no significant effect on reduction of blood pressure and renal function. ${ }^{19}$ In our study the eGFR was significantly improved in the intervention group compared with the control group at three months after baseline. This reflected an improvement in renal function among patients of the intervention group. Moreover, our study supports the previous metaanalysis of randomized-controlled trials on the reduction of blood pressure is an effective strategy to preventing cardiovascular events among people with moderately reduced $\mathrm{eGFR}^{20}$ and the study also showed that patients with eGFR $<60 \mathrm{~mL} / \mathrm{min} / 1.73 \mathrm{~m} 2$ who were aware of reduction of salty diet and health-related behavior were more likely to reach blood pressure controlled recommendation. ${ }^{20,21}$

Approximately 2.5 million hypertensive patients in Thailand receive treatment but fail to control their blood 
pressure. This might be the result of various factors. Such factors include: the inconvenience of travel to the hypertension clinic from a remote area, long waiting times for treatment, irregular use of medication, fear of side effects, use of expired medication, and confusion regarding the various doses and medications.

The multidisciplinary approach in this study addressed all the root causes of uncontrolled blood pressure problems among the patients. The present study proved that the multidisciplinary approach, and the efforts of multidisciplinary health-care providers to provide comprehensive information and intensive intervention through patient-centric care close to home, can improve blood pressure control among elderly hypertensive patients. The multidisciplinary intervention program was useful in helping patients with a history of uncontrolled blood pressure and poor adherence to effectively control their blood pressure, improve medication adherence, and maintain normal kidney function.

The present findings are consistent with those of previous studies on factors related to the control of blood pressure. One of the key factors related to blood pressure control is the lack of time among health-care providers to provide information or thoroughly answer patients' questions. This could lead to misinformation and the patient's decision to discontinue follow-up treatment. Earlier studies have shown that patients with hypertension who show good adherence to antihypertensive medications tend to maintain appropriate blood pressure levels and renal function. People who adhere to antihypertensive medication regimens are $45 \%$ more likely to achieve blood pressure control. ${ }^{22-24}$

Our findings demonstrate similar results to other studies that employed multidisciplinary approach intervention programs that involved intensive hypertension care and services by multidisciplinary health-care providers, family and community participation focused on long-term lifestyle modification, with the consumption of healthy foods with low sodium and fat, sufficient fruits and vegetables, regular physical activity, adequate control of stress, and improved antihypertension adherence. ${ }^{25-27}$

To our knowledge, this is the first study to use a multidisciplinary intervention to improve blood pressure control in elderly hypertensive patients in the primary health care system under the UHC in rural Thailand. Our findings demonstrate that very intensive intervention by integrating a comprehensive multidisciplinary approach, based on the various causes of uncontrolled blood pressure into routine care, could be more effective than a single approach. Moreover, in an environment with limited resources, the multidisciplinary approach may be feasible for routine practice in the primary health care unit, especially in rural areas where access to health care facilities is a challenge.

For future studies, the cost-effectiveness of integrating multidisciplinary approach interventions in routine hypertension care service for elderly hypertensive patients in the primary health care system, should be investigated. And the lifestyle modification assessment especially diet and exercises should be assessed and explore the relationship with controlling of blood pressure among elderly patients.

\section{Study Limitation}

The finding of this study must be considered within the following limitation. The quasi-experimental design cannot be fully generalization of the effect of the intervention, the cluster randomization should be a better design for this study. The distance between intervention and control group is approximately 10 kilometers which may lead to the contamination of the knowledge and information between the intervention and control groups.

\section{Conclusion}

The present study demonstrated that a multidisciplinary intervention program is more effective than an in-clinic hypertension care service and education program in improving blood pressure control among elderly hypertensive patients. A multidisciplinary approach should be applied in routine hypertensive care services in primary health care facilities, to improve the quality of care and access to health care under the UHC.

\section{Acknowledgments}

This study was supported by the 100th Anniversary of Chulalongkorn University Scholarship and the 90th Anniversary of Chulalongkorn University Scholarship.

The authors thank Buengkan Hospital, Buengkan District Health Office, and Noonsomboon Health Center (Health Promoting hospital) for providing support during data collection.

\section{Disclosure}

The authors report no conflicts of interest in this work.

\section{References}

1. Campbell NR, Khalsa T, Lackland DT, et al. High blood pressure 2016: why prevention and control are urgent and important. J Clin Hypertens. 2016;18(8):714-717. doi:10.1111/jch.12840 
2. Tibazarwa KB, Damasceno AA. Hypertension in developing countries. Can J Cardiol. 2014;30(5):527-533. doi:10.1016/j.cjca.2014.02.020

3. Charoendee K, Sriratanaban J, Aekplakorn W, Hanvoravongchai P. Assessment of population coverage of hypertension screening in Thailand based on the effective coverage framework. BMC Health Serv Res. 2018;18(1):208. doi:10.1186/s12913-018-2996-y

4. Aekplakorn W, Sangthong R, Kessomboon P, et al. Changes in prevalence, awareness, treatment and control of hypertension in Thai population, 2004-2009: Thai National Health Examination Survey III-IV. J Hypertens. 2012;30(9):1734-1742. doi:10.1097/ HJH.0b013e3283568158

5. Ibrahim MM, Damasceno A. Hypertension in developing countries. Lancet. 2012;380(9841):611-619. doi:10.1016/S0140-6736(12)60861-7

6. Thaiprayoon S, Wibulpolprasert S. Political and policy lessons from Thailand's UHC experience. Obs Res Found Issue Brief. 2017;25 (174):5-6.

7. Limwattananon S, Tangcharoensathien V, Tisayaticom K, Boonyapaisarncharoen T, Prakongsai P. Why has the Universal Coverage Scheme in Thailand achieved a pro-poor public subsidy for health care. BMC Public Health. 2012;12 Suppl 1(Suppl 1):S6. doi:10.1186/1471-2458-12-S1-S6

8. Roubsanthisuk W, Silaruks S, Ophascharoensuk V, Sirinak C, Phrommayon P. Hypertension in Thailand: a message from the Thai hypertension society on world hypertension day 2017. J Med Assoc Thai. 2018;101(5):705-706.

9. Areechokchai D, Vijitsoonthornkul K, Pongpan S, Maeakhian S. Population attributable fraction of stroke risk factors in Thailand: utilization of non-communicable disease surveillance systems. Outbreak Surveillance Invest Rep J. 2017;10(1):1-6.

10. Bootsri S, Nakornkate K, Sukonthasab SA. Contribution of PAR for the prevention and control of hypertension and diabetes among the Elderly in Thailand. Glob J Health Sci. 2016;9(6):p76. doi:10.5539/ gjhs.v9n6p76

11. Suwanwela NC. Stroke epidemiology in Thailand. J Stroke. 2014;16 (1):1. doi:10.5853/jos.2014.16.1.1

12. Nidhinandana S, Ratanakorn D, Charnnarong N, Muengtaweepongsa S, Towanabut S. i-STROKE investigators. Blood pressure control among stroke patients in Thailand the i-STROKE study. J Stroke Cerebrovasc Dis. 2014;23(3):476-478. doi:10.1016/j.jstrokecerebrovasdis.2013.04. 006

13. Sakboonyarat B, Rangsin R, Kantiwong A, Mungthin M. Prevalence and associated factors of uncontrolled hypertension among hypertensive patients: a nation-wide survey in Thailand. BMC Res Notes. 2019;12(1):380.

14. Rahman AR, Wang JG, Kwong GM, Morales DD, Sritara P, Sukmawan R. Perception of hypertension management by patients and doctors in Asia: potential to improve blood pressure control. Asia Pac Fam Med. 2015;14(1):2. doi:10.1186/s12930-015-0018-3

15. Heidenreich PA. Patient adherence: the next frontier in quality improvement. Am J Med. 2004;117(2):130-132. doi:10.1016/j. amjmed.2004.03.007
16. Baena CP, Olandoski M, Younge JO, et al. Effects of lifestyle-related interventions on blood pressure in low and middle-income countries: systematic review and meta-analysis. $J$ Hypertens. 2014;32 (5):961-973. doi:10.1097/HJH.0000000000000136

17. Woodham N, Taneepanichskul S, Somrongthong R, Auamkul N. Medication adherence and associated factors among elderly hypertension patients with uncontrolled blood pressure in rural area, Northeast Thailand. J Health Res. 2018;32(6):449-458. doi:10.1108/JHR-11-2018-085

18. Lee JK, Grace KA, Taylor AJ. Effect of a pharmacy care program on medication adherence and persistence, blood pressure, and low-density lipoprotein cholesterol: a randomized controlled trial. J Am Med Assoc. 2006;296(21):2563-2571. doi:10.1001/jama.296.21.joc60162

19. Ettehad D, Emdin CA, Kiran A, et al. Blood pressure lowering for prevention of cardiovascular disease and death: a systematic review and meta-analysis. Lancet. 2016;387(10022):957-967. doi:10.1016/ S0140-6736(15)01225-8

20. Trialists'Collaboration BP. Blood pressure lowering and major cardiovascular events in people with and without chronic kidney disease: meta-analysis of randomised controlled trials. Br Med J. 2013;347: f5680. doi:10.1136/bmj.f5680

21. Ravera M, Noberasco G, Weiss U, et al. CKD awareness and blood pressure control in the primary care hypertensive population. $\mathrm{Am}$ J Kidney Dis. 2011;57(1):71-77. doi:10.1053/j.ajkd.2010.08.022

22. Go AS, Bauman MA, King SMC, et al. An effective approach to high blood pressure control: a science advisory from the American Heart Association, the American College of Cardiology, and the Centers for Disease Control and Prevention. Hypertension. 2014;63(4):878-885. doi:10.1161/HYP.0000000000000003

23. James PA, Oparil S, Carter BL, et al. Evidence-based guideline for the management of high blood pressure in adults: a report from the panel members appointed to the Eighth Joint National Committee. $J$ Am Med Assoc. 2014;311(5):507-520. doi:10.1001/jama.2013.284427

24. Joffres M, Falaschetti E, Gillespie C, et al. Hypertension prevalence, awareness, treatment and control in national surveys from England, the USA and Canada, and correlation with stroke and ischaemic heart disease mortality: a cross-sectional study. Br Med J. 2013;3(8):e003423.

25. Ellis RJB, Knisely MR, Boyer K, Pike C. Pillbox intervention fidelity in medication adherence research: a systematic review. Nurs Outlook. 2017;65(4):464-476. doi:10.1016/j.outlook.2016.12.011

26. Hamdidouche I, Jullien V, Boutouyrie P, Billaud E, Azizi M, Laurent S. Drug adherence in hypertension: from methodological issues to cardiovascular outcomes. $J$ Hypertens. 2017;35 (6):1133-1144. doi:10.1097/HJH.0000000000001299

27. Visanuyothin S, Plianbangchang S, Somrongthong R. An integrated program with home blood-pressure monitoring and village health volunteers for treating poorly controlled hypertension at the primary care level in an urban community of Thailand. Integr Blood Press Control. 2018;11:25. doi:10.2147/IBPC.S160548

28. Proia KK, Thota AB, Njie GJ, et al. Team-based care and improved blood pressure control: a community guide systematic review. $\mathrm{Am}$ J Prev Med. 2014;47(1):86-87. doi:10.1016/j.amepre.2014.03.004
Journal of Multidisciplinary Healthcare

\section{Publish your work in this journal}

The Journal of Multidisciplinary Healthcare is an international, peerreviewed open-access journal that aims to represent and publish research in healthcare areas delivered by practitioners of different disciplines. This includes studies and reviews conducted by multidisciplinary teams as well as research which evaluates the results or conduct of such teams or healthcare processes in general. The journal covers a very wide range of areas and welcomes submissions from practitioners at all levels, from all over the world. The manuscript management system is completely online and includes a very quick and fair peer-review system. Visit http://www.dovepress.com/testimonials. php to read real quotes from published authors. 